\title{
Esophageal duplication cyst causing megaesoph- agus in a young woman presenting with dysphagia
}

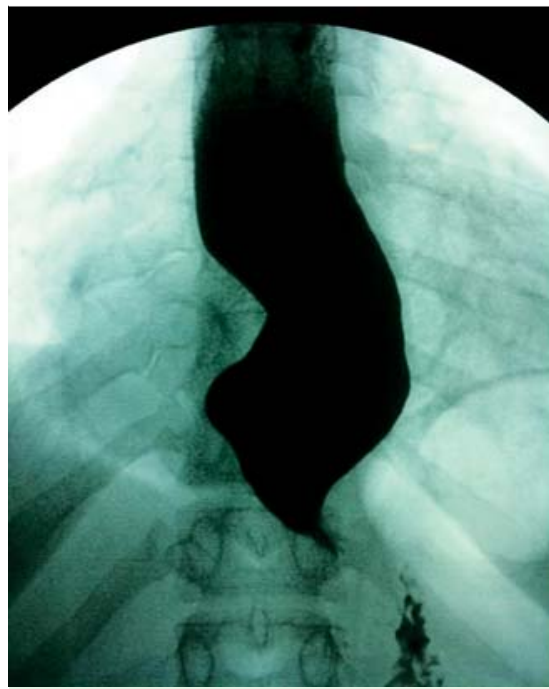

Fig. 1 Barium esophagram suggesting megaesophagus.

A 35-year-old woman had dysphagia to solids for 6 months. Barium esophagram suggested megaesophagus ( $\bullet$ Fig. $\mathbf{1}$ ), and endoscopy ( Fig.2) showed bulging of the distal esophagus, suggesting extrinsic compression. The patient had no epidemiologic background for Chagas disease. Computed tomography (CT) showed a hypodense lesion in the posterior mediastinum, adjacent to the left atrium and lower esophagus ( Fig. 3).

The patient was referred for endoscopic ultrasound (EUS), which showed an anechoic, homogeneous lesion measuring $49 \mathrm{~mm}$ in the distal esophagus, inside the esophageal wall ( Fig.4). EUS-guided fine-needle aspiration (EUS-FNA) of the cyst ( Fig.5) obtained a mucoid fluid and small tissue fragments of the cystic wall. Histopathological examination showed cuboidal cells. The patient underwent thoracotomy with cyst excision from the wall of the lower esophagus with no complications. Histopathological examination showed evidence of two muscle layers and cuboidal cells, confirming the diagnosis of esophageal duplication cyst. After 1 year's follow-up, the patient is asymptomatic and the appearance on upper endoscopy is normal.

Esophageal duplication cysts are rare congenital anomalies, most frequently located in the right posterior mediastinum at the level of the distal third of the esopha-

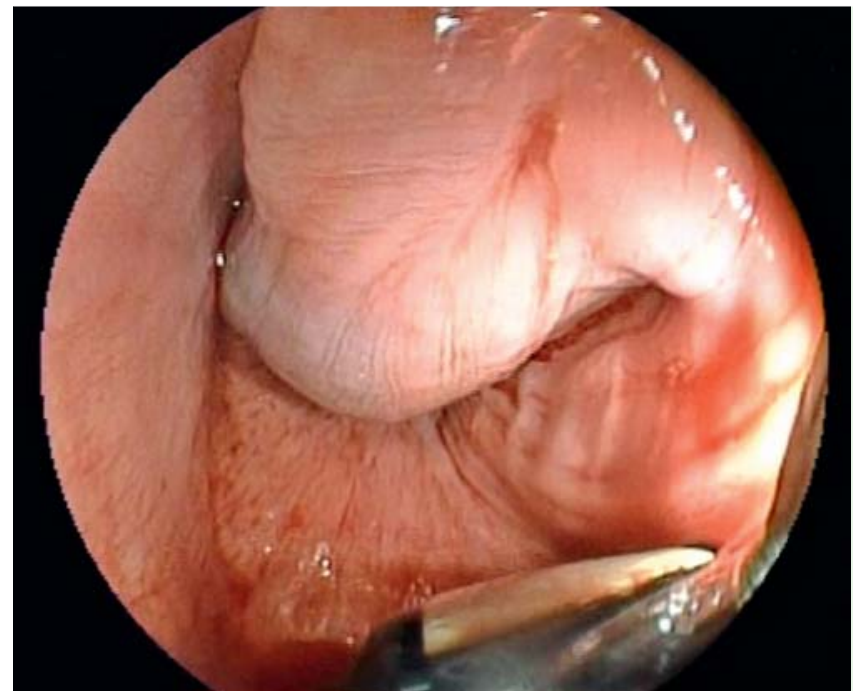

Fig.2 Endoscopy

image showing a bulge in the distal esophagus.

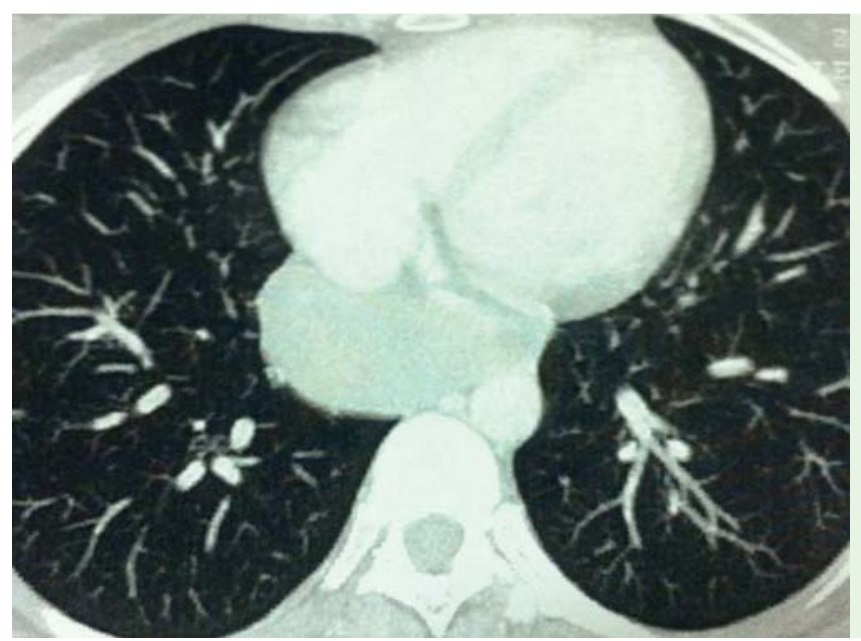

Fig. 3 Computed tomography showing a hypodense lesion located in the posterior mediastinum, adjacent to the left atrium and lower esophagus.

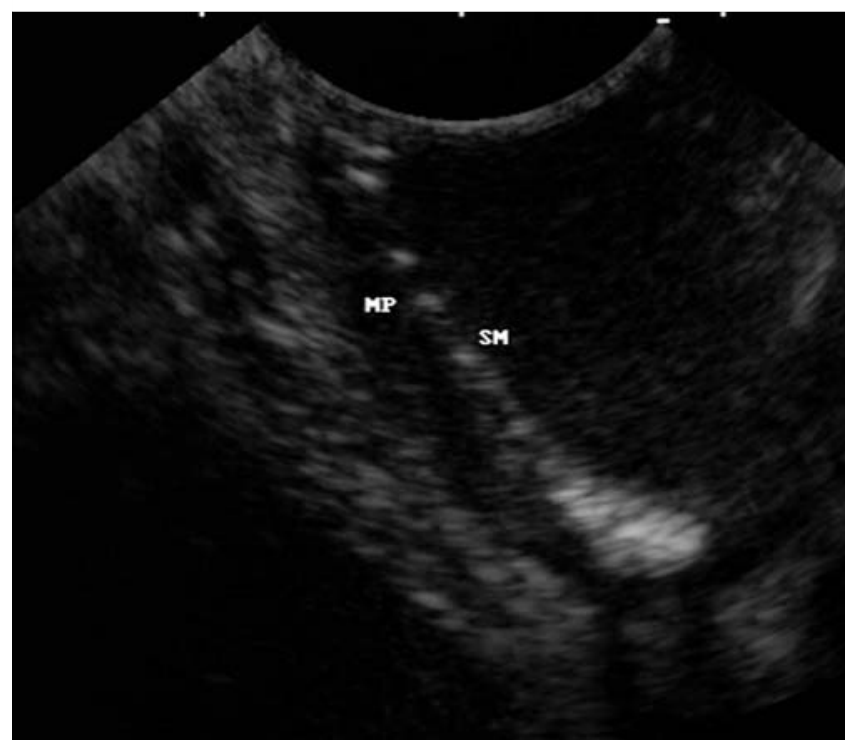

Fig. 4 Endoscopic ultrasound showing the submucosa and muscularis propria of the esophageal duplication cyst. 


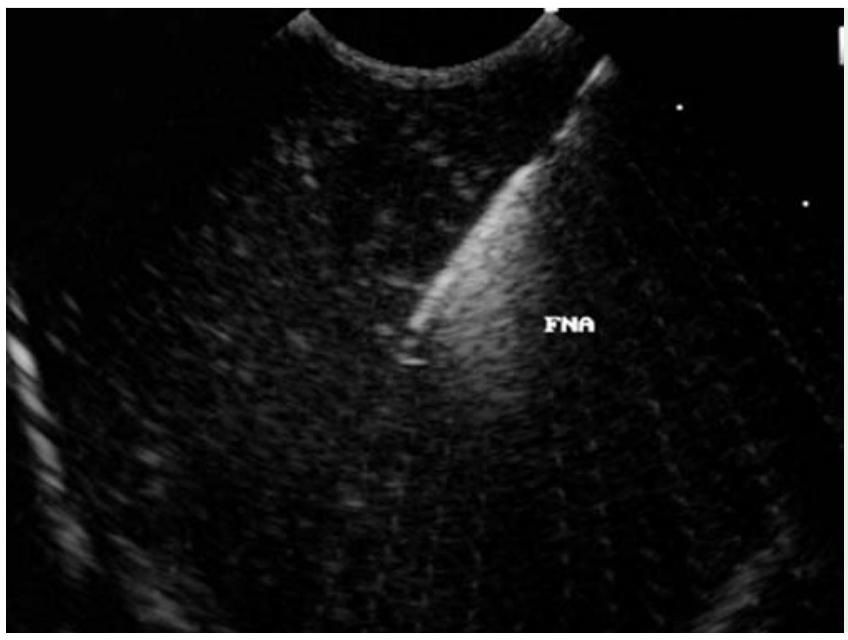

gus $[1,2]$. The cysts are lined by squamous, columnar, cuboidal, pseudostratified, or ciliated epithelium. They are covered by two thick muscle layers which are in contiguity with the muscularis propria. Because this condition is rare, it is sometimes not diagnosed or is confused with other diseases [3]. EUS can be helpful for preoperative diagnosis by demonstrating a cystic lesion with an intimate attachment to the esophageal wall and the presence of a smooth muscle coat.

In the present case we were able to demonstrate an esophageal duplication cyst causing megaesophagus clinically and radiologically.
Fig. 5 Endoscopic ultrasound-guided fine-needle aspiration of the esophageal duplication cyst.

\section{References}

1 Cioffi $U$, Bonavina L, Simone $M$ et al. Presentation and surgical management of bronchogenic and esophageal duplication cysts in adults. Chest 1998; 113: $1492-$ 1496. doi: $10.1378 /$ chest.113.6.1492

2 Procházka V, Kala Z, Novotný I et al. Laparoscopic management of an infected oesophageal cyst. Rozhl Chir 2005; 84: 526-528

3 Ringley C, Bochkarev V, Oleynikov D. Esophageal duplication cyst - a guest case in robotic and computer-assisted surgery from the University of Nebraska Medical Center. MedGenMed 2006; 8: 25

\section{Bibliography}

DOI http://dx.doi.org/

10.1055/s-0034-1365288

Endoscopy 2014; 46: E201-E202

(c) Georg Thieme Verlag KG

Stuttgart · New York

ISSN 0013-726X

Competing interests: None

\section{Augusto Carbonari, Marcelo Frota, Rogerio Colaiacovo, Lucio Rossini, Romeu Nakamura}

Irmandade da Santa Casa de Misericordia de São Paulo - Department of Endoscopy and French-Brazilian Centre of Endoscopic Ultrasound (CFBEUS), São Paulo, São Paulo, Brazil

\section{Corresponding author}

\section{Augusto Carbonari, MD}

Irmandade da Santa Casa de Misericordia de São Paulo

Department of Endoscopy and French-Brazilian Centre of Endoscopic Ultrasound (CFBEUS) Rua Manuel Figueiredo Landim 600 ap 52A São Paulo

São Paulo 04693-130

Brazil

Fax: +55-19-996040645

augustocarbonari@gmail.com 